\title{
PROYEKSI KEBUTUHAN AIR BERSIH PADA TAHUN 2021 DI KOTA PULANG PISAU MENGGUNAKAN METODE ARITMATIK
}

\author{
Miming Virganinda Burako \\ Program Studi Teknik Sipil, Universitas Kristen Palangka Raya \\ e-mail: mimingvirganinda@ yahoo.co.id
}

\begin{abstract}
ABSTRAK
Sistem pengelolaan air bersih di Pulang Pisau di kelola Perusahaan Daerah Air Minum (PDAM) Pulang Pisau. Sistem pengolahan air bersih ini dibuat untuk memberikan pelayanan kepada penduduk kota dan sekitarnya guna pemenuhan kebutuhan akan air bersih. Perusahaan Daerah Air Minum (PDAM) Pulang Pisau saat ini memiliki kapasitas terpasang $45 \mathrm{lt} / \mathrm{dt}$ sedangkan kapasitas terpakai $33 \mathrm{lt} / \mathrm{dt}$. Dengan bertambahnya jumlah penduduk dan mapannya perekonomian penduduk, maka kebutuhan air bersih yang bertujuan untuk mengetahui jumlah debit air bersih dan tingkat pelayanan bagi penduduk saat ini maupun dimasa yang akan datang agar tidak ditemukan kekurangan dan kelebihan produksi air bersih.

Kebutuhan akan air bersih kota Pulang Pisau dilakukan dengan menggunakan metode standard debit minimum air bersih sesuai kriteria kota ditinjau dari jumlah penduduk dan mengetahui unjuk kerja (performance) layanan jaringan air bersih untuk kota Pulang Pisau dengan menganalisis kebutuhan air bersih pada jaringan, kemampuan layanan jaringan dalam memenuhi kebutuhan minimum pelanggan dan penduduk, berdasarkan standard debit minimum..

Untuk kemampuan layanan terhadap pelanggan PDAM Pulang Pisau pada tahun 2018 melayani melayani 1.995 pelanggan (sambungan) yang terdiri dari 1.862 pelanggan non niaga, 24 pelanggan niaga kecil, 7 pelanggan niaga besar, 18 pelanggan sosial, 13 pelanggan kran umum dan 55 pelanggan instansi pemerintah, 16 Hidran umum dengan kapasitas alat terpasang 45 lt/dt sedangkan yang terpakai 33 lt/dt. Untuk tahun 2021 PDAM Pulang Pisau menargetkan layanan $45 \%$ jumlah penduduk, dengan penduduk 32.514 jiwa yaitu 14.631 jiwa. PDAM Pulang Pisau memberikan tingkat pelayanan yang cukup memuaskan dengan prosentase sekitar $216 \%$ dimana kapasitas produksi sebesar 33 lt/dt dengan konsumsi pelanggan 15,24 1t/det . Dari penelitian ini dapat disimpulkan bahwa kebutuhan akan air bersih meningkat sehingga perlu penambahan kapasitas produksi serta pelayanan jaringan air bersih oleh pihak Perusahaan Daerah Air Minum (PDAM) Pulang Pisau sesuai dengan waktu penelitian untuk debit sudah dapat memenuhi harapan.
\end{abstract}

Kata Kunci : $\quad$ Air Bersih, Kebutuhan Air Bersih, Kapasitas Alat, Kapasitas Produksi, Standar Debit Minimum. 


\section{PENDAHULUAN}

Air merupakan kebutuhan yang sangat penting bagi kelangsungan hidup manusia, tanpa air tidak akan ada kehidupan di bumi. Tubuh manusia $65 \%$ nya terdiri atas air. Bumi mengandung sejumlah besar air, lebih kurang 1,4 x $109 \mathrm{~km}^{3}$, yang terdiri atas samudera, laut, sungai, danau, gunung es, dan sebagainya. Namun dari sekian banyak air yang terkandung di bumi hanya $3 \%$ yang berupa air tawar yang terdapat dalam sungai, danau, dan air tanah.

Karena pentingnya kebutuhan akan air bersih, maka adalah hal yang wajar jika sektor air bersih mendapatkan prioritas penanganan utama karena menyangkut kehidupan orang banyak. Penanganan akan pemenuhan kebutuhan air bersih dapat dilakukan dengan berbagai cara, disesuaikan dengan sarana dan prasarana yang ada.

Demikian halnya pula dengan kota Pulang Pisau, Perusahaan Daerah Air Minum (PDAM) Pulang Pisau sebelumnya merupakan unit PDAM Kabupaten Kapuas, namun seiring dengan ditetapkannya UU No 5 tahun 2002 tentang pembentukan Kabupaten Katingan, Kabupaten Seruyan, Kabupaten Pulang Pisau, Kabupaten Lamandau, Kabupaten Gunung Mas, Kabupaten Murung Raya, Kabupaten Pulang Pisau dan Kabupaten Barito Timur di Provinsi Kalteng maka PDAM Kabupaten Kapuas menyerahkan pengelolaan air minum di wilayah Pulang Pisau kepada pemerintah daerah Kabupaten Pulang Pisau. PDAM Pulang Pisau merupakan penyedia air bersih di daerah ini, yang terus berupaya meningkatkan jumlah produksinya seiring dengan bertambahnya kebutuhan akan air bersih, dan terus meningkatkan pelayanan kepada masyarakat sehingga diharapkan nantinya seluruh kebutuhan dan kepuasan di masyarakat dapat terpenuhi dengan baik.

Berdasarkan permasalahan tersebut, dipandang perlu untuk mengetahui jumlah kebutuhan air bersih di kota Pulang Pisau pada saat ini maupun di masa yang akan datang, serta untuk mengetahui sejauh mana tingkat pelayanan jaringan Perusahaan Daerah Air Minum (PDAM) melayani kebutuhan masyarakat pada saat ini sehingga kedepannya nanti Perusahaan Daerah Air Minum (PDAM) dapat meningkatkan pelayanannya dengan demikian diharapkan jumlah air bersih yang diproduksi oleh Perusahaan Daerah Air Minum (PDAM) Pulang Pisau dapat menyediakan seluruh kebutuhan masyarakat.

\section{Rumusan Masalah}

Rumusan masalah penelitian ini adalah sebagai berikut :

1. Bagaimana tingkat pelayanannya untuk pelanggan dan penduduk kota Pulang Pisau akan kebutuhan air bersih.

2. Bagaimana tingkat kebutuhan air bersih untuk kota Pulang Pisau dalam jangka waktu 3 tahun yang akan datang.

\section{Maksud dan Tujuan}

Maksud penelitian ini adalah untuk mengetahui jumlah debit air bersih dan tingkat pelayanan sistem yang dibutuhkan masyarakat kota Pulang Pisau saat ini maupun di masa yang akan datang, sehingga tidak ditemukan kekurangan dan kelebihan produksi air bersih yang dapat merugikan masyarakat maupun pihak Perusahaan Daerah Air Minum (PDAM) Pulang Pisau.

Tujuan dari penelitian ini adalah sebagai berikut :

1. Mengetahui tingkat kemampuan pelayanan PDAM terhadap pelanggan dan penduduk kota Pulang Pisau.

2. Mengetahui tingkat kebutuhan air bersih untuk kota Pulang Pisau selama 3 tahun mendatang.

\section{Batasan Masalah}

Permasalahan hanya dibatasi pada lingkup pengumpulan data penggunaan air dan produksi air minum PDAM kota Pulang Pisau.

\section{TINJAUAN PUSTAKA}

\section{Sumber Air Bersih}

Sumber air permukaan PDAM Kota Pulang Pisau diperoleh dari Sungai Kahayan. Sumber air ini mempunyai kontribusi paling besar dalam penyediaan air bersih di kota Pulang Pisau, syarat sumber air bersih yang baik adalah :

1. Sumber ada sepanjang waktu.

2. Pengaruh sumber air terhadap perencanaan jaringan.

3. Kualitas. 
4. Kondisi air baku.

5. Jumlah air sumber atau sama dengan jumlah air kebutuhan.

6. Rata-rata debit minimum sumber dalam satu hari lebih besar atau sama dengan rata-rata debit kebutuhan.

7. Debit air sumber yang ada masih memberikan sejumlah air guna kepentingan di luar perencanaan sistem penyediaan air bersih.

\section{Kriteria Debit Air Bersih}

Berdasarkan kebijakan pembangunan air bersih, maka kebutuhan air pada suatu kota didasarkan pada besarnya jumlah penduduk yang dilayani dikalikan dengan tingkat pelayanan/kebutuhan perkapita sesuai dengan klasifikasi kota dengan mempertimbangkan kebutuhan untuk non domestik seperti sosial, komersial, industri, dan sektor lainnya.

Menurut DPU pedoman konsumsi air adalah seperti tercantum pada tabel berikut ini.

Tabel 1 Standar Debit Air Bersih

\begin{tabular}{|c|l|r|c|}
\hline No. & Kategori Kota & $\begin{array}{c}\text { Jumlah penduduk } \\
\text { (orang) }\end{array}$ & $\begin{array}{c}\text { Konsumsi Air } \\
\text { (It/orang/hari) }\end{array}$ \\
\hline 1. & Metropolitan & $\geq 5.000 .000$ & 210 \\
2. & Besar & $1.000 .000-5.000 .000$ & 170 \\
3. & Sedang & $100.000-1.000 .000$ & 150 \\
4. & Kecil & $20.000-100.000$ & 90 \\
\hline
\end{tabular}

Sumber : DPU (1989)

Standar air bersih untuk kota Pulang Pisau dapat ditentukan berdasarkan kategori kota dengan jumlah penduduk kota Pulang Pisau tahun 2008 sebesar 30.170 jiwa, dan apabila dilihat dari jumlah penduduk kota Pulang Pisau tersebut, maka kota Pulang Pisau termasuk dalam kategori kota IV yaitu kota kecil dengan standart konsumsi air minimal 90 lt/orang/hari, dengan asumsi rata-rata penghuni/pelanggan adalah sebesar 4 orang, sehingga diketahui debit minimum adalah 11 $\mathrm{m}^{3} /$ pelanggan/bulan. Dengan demikian, debit minimum yang digunakan sebagai dasar dalam menganalisa yang harus dikeluarkan oleh pihak PDAM adalah sebesar $11 \mathrm{~m}^{3} /$ bulan dengan perhitungan bahwa kebutuhan air (consumtive use) adalah 90 lt/orang/hari .

\section{METODE PENELITIAN}

\section{Uraian}

Penyusunan Penelitian ini dilaksanakan dengan mengikuti tahapan-tahapan penelitian, yaitu identifikasi pokok masalah penelitian, studi literatur, teknik pengumpulan data, analisa data, kesimpulan dan saran.

\section{Identifikasi Pokok Permasalahan Penelitian}

Sebuah penelitian selalu berangkat dari sebuah pokok permasalahan yang akan dijadikan obyek bahasan dalam penelitian. Dalam penelitian ini pokok masalah yang akan diangkat adalah berapa jumlah tingkat kebutuhan air bersih di kota Pulang Pisau dan sudah sejauh mana PDAM melayani kebutuhan air bersih di daerah ini.

\section{Studi Literatur}

Studi pustaka mutlak diperlukan dalam sebuah penelitian ilmiah. Studi literatur diperlukan untuk memecahkan suatu permasalahan yang ada dan menentukan kebutuhan data yang diperlukan sekaligus memberikan metode pemecahan masalah yang akan dijadikan objek. Dengan studi literatur teori-teori dan uraian penjelasan yang ada hubungannya dengan kebutuhan air dan pelayanan dapat dipakai sebagai dasar untuk menganalisis perhitungan.

\section{Teknik Pengumpulan data}

Dalam penyusunan dan penanganan suatu permasalahan mutlak diperlukan adanya data (input data) yang menunjang, agar data tersebut dapat diolah dalam perhitungan, sehingga dapat menghasilkan suatu hasil pemecahan dengan baik dan tepat. Adapun cara memperoleh data tersebut adalah dengan meninjau dan pengamatan secara langsung ke lokasi penelitian dan memperoleh data dari instansi yang terkait, dalam hal ini adalah Perusahaan Daerah Air Minum (PDAM) Kabupaten Pulang Pisau dan Badan Pusat Statistik (BPS) Kabupaten Pulang Pisau. Adapun data yang dibutuhkan dalam penulisan penelitian ini meliputi 


\section{Data Pelanggan}

Pelanggan PDAM merupakan pengguna/pengkonsumsi air yang telah dikelola dan diproduksi oleh PDAM, kemudian di distribusikan oleh PDAM. Pelanggan PDAM ini terdiri dari sambungan rumah dan sambungan pemerintah. Dengan adanya data jumlah pelanggan dapat diketahui kemampuan PDAM kota Pulang Pisau dalam melayani kebutuhan para pelanggan. Saat ini perusahaan Daerah Air Minum (PDAM) Pulang Pisau mempunyai pelanggan berjumlah 1995 pelanggan yang terdiri dari 1862 sambungan rumah tangga dan 133 sambungan lainnya

\section{Data Kapasitas Produksi}

Data kapasita produksi adalah data kemampuan PDAM Pulang Pisau untuk memproduksi air bersih. Adapun kapasitas produksi Perusahaan Daerah Air Minum (PDAM) Pulang Pisau yang sedang beroperasi pada tahun 2011 adalah 33 liter/detik.

\section{Data Produksi}

Data produksi merupakan data jumlah total air yang telah didistribusikan kepada pelanggan. Untuk data produksi ini diperoleh dari kantor Perusahaan Daerah Air Minum (PDAM) Pulang Pisau.

\section{Data Penerimaan Air Pelanggan}

Data penerimaan air pelanggan merupakan data jumlah air yang telah diterima oleh seluruh pelanggan Perusahaan Daerah Air Minum (PDAM) Pulang Pisau perbulan yang tercatat di alat meteran.

\section{Data Penduduk}

Data penduduk kota Pulang Pisau diperlukan guna mengetahui sejauh mana kemampuan PDAM melayani kebutuhan air bersih terhadap penduduk kota Pulang Pisau, dimana saat ini penduduk kota Pulang Pisau relatif sedikit mengkonsumsi air bersih produksi PDAM Pulang Pisau. Data penduduk diperoleh dari Kantor Badan Pusat Statistik (BPS) Kabupaten Pulang Pisau. Untuk analisis perhitungan proyeksi jumlah penduduk mendatang diperlukan data jumlah penduduk pada tahun sebelumnya, dalam penulisan penelitian ini diambil data penduduk mulai dari tahun 2012 sampai dengan tahun 2021.

\section{Proyeksi Pertumbuhan Penduduk}

Proyeksi jumlah penduduk diperlukan untuk dapat memperhatikan jumlah penduduk suatu kota di masa yang akan datang. Masingmasing cara mempunyai karakteristik tersendiri, sehingga nantinya dapat dipilih salah satu cara yang tepat melalui beberapa metode sebagai dasar pemilihan. Dalam Penelitian ini, proyeksi pertumbuahan jumlah penduduk menggunakan Metode Aritmatika.

\section{Metode Aritmatika}

Rumus yang digunakan dalam metode aritmatika adalah sebagai berikut :

$$
\begin{aligned}
\mathrm{Pt} & =\mathrm{Po}+\text { Pr.n } \\
\operatorname{Pr} & =\frac{\mathrm{Po}-\mathrm{Pn}}{\mathrm{n}}
\end{aligned}
$$

Tabel 2 Jumlah Penduduk Kota Pulang Pisau Tahun 2015 - 2017

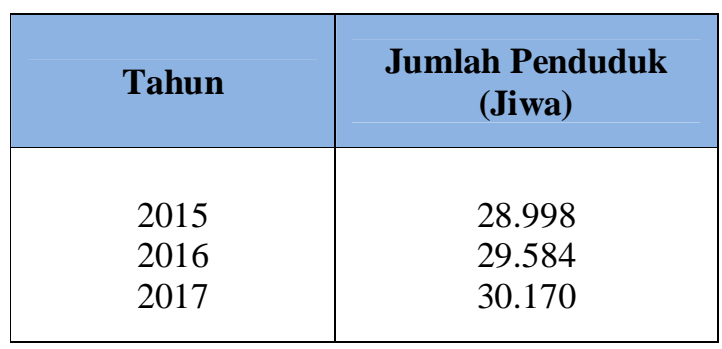

Sumber: hasil perhitungan

$$
\begin{aligned}
\text { Pt } & =\text { Po }+(\text { Pr.n }) \\
\operatorname{Pr} & =\text { Po }- \text { Pn } \\
& =\left[\frac{30.170-28.998}{2017-2015}\right] \\
& =\left[\frac{1.172}{2}\right]=586 \\
& =30.170+(586 \times \mathrm{n}) \\
& =30.170+(586 \times 1) \\
& =30.756
\end{aligned}
$$$$
\text { Pt2018=30.170+(586 } \times \text { n })
$$ 
Proyeksi Kebutuhan Air Bersih Pada Tahun 2021 ..., Miming

Tabel 3 Proyeksi Jumlah Penduduk Kota Pulang Pisau Tahun 2018 - 2021 dengan Metode Aritmatik

\begin{tabular}{|c|c|}
\hline Tahun & $\begin{array}{c}\text { Jumlah Penduduk } \\
\text { (Jiwa) }\end{array}$ \\
\hline 2018 & 30.756 \\
2019 & 31.342 \\
2020 & 31.928 \\
2021 & 32.514 \\
\hline
\end{tabular}

Sumber : Hasil Perhitungan

Guna memenuhi kebutuhan air bersih Kota Pulang Pisau perencanaan tiga tahun yang akan datang, Pemerintah Kabupaten Pulang Pisau menargetkan pelanggan air bersih sebesar $45 \%$ dari jumlah penduduk Kota Pulang Pisau, sedangkan sisanya menggunakan sumur.

Tabel 4 Target Layanan PDAM Sebesar 45\%

\begin{tabular}{|c|c|c|}
\hline Tahun & $\begin{array}{c}\text { Jumlah } \\
\text { Proyeksi } \\
\text { Penduduk } \\
\text { (Jiwa) }\end{array}$ & $\begin{array}{c}\text { Layanan } \\
\text { PDAM 45\% } \\
\text { (Jiwa) }\end{array}$ \\
\hline 2018 & 30.756 & 13.840 \\
2019 & 31.342 & 14.103 \\
2020 & 31.928 & 14.367 \\
2021 & 32.514 & 14.631 \\
\hline
\end{tabular}

Sumber : Hasil Perhitungan

\section{Tahun 2018}

Konsumsi Air Pelanggan $=13.840 \times 90$ lt/org/hari

$$
=14,42 \mathrm{lt} / \mathrm{dt}
$$

Kapasitas alat $33 \mathrm{lt} / \mathrm{dt}$

Layanan PDAM terhadap pelanggan :

$$
\frac{33 \mathrm{lt} / \mathrm{dt}}{14,42 \mathrm{lt} / \mathrm{dt}} \times 100 \%=228 \%
$$

Tahun 2019

Konsumsi Air Pelanggan $=14.103 \times 90$ lt/org/hari

$$
\begin{aligned}
& =1.269 .270 \mathrm{lt} / \text { hari } \\
& =14,69 \mathrm{lt} / \mathrm{dt}
\end{aligned}
$$

Kapasitas alat $33 \mathrm{lt} / \mathrm{dt}$

Layanan PDAM terhadap pelanggan :

$$
\frac{33 \mathrm{lt} / \mathrm{dt}}{14,69 \mathrm{lt} / \mathrm{dt}} \times 100 \%=224 \%
$$

Tahun 2020

Konsumsi Air Pelanggan $=\quad 14.367 \times 90$ lt/org/hari

$=\quad 1.293 .030 \mathrm{lt} / \mathrm{hari}$

$=\quad 14,96 \mathrm{lt} / \mathrm{dt}$

Kapasitas alat $33 \mathrm{lt} / \mathrm{dt}$

Layanan PDAM terhadap pelanggan :

$$
\frac{33 \mathrm{lt} / \mathrm{dt}}{14,96 \mathrm{lt} / \mathrm{dt}} \times 100 \%=220 \%
$$

\section{Tahun 2021}

Konsumsi Air Pelanggan $=\quad 14.631 \times 90$ 1t/org/hari

\begin{tabular}{|c|c|c|c|}
\hline Tahun & $\begin{array}{l}\text { Layanan } \\
45 \% \text { Jiwa }\end{array}$ & $\begin{array}{c}\text { Konsumsi } \\
\text { Pelanggan } \\
\text { (lt/dt) }\end{array}$ & $\begin{array}{c}\text { Prosentase } \\
\text { Layanan } \\
(\%)\end{array}$ \\
\hline 2018 & 13.840 & 14,42 & 228 \\
\hline 2019 & 14.103 & 14,69 & 224 \\
\hline 2020 & 14.367 & 14,96 & 220 \\
\hline 2021 & 14.631 & 15,24 & 216 \\
\hline
\end{tabular}

$$
\begin{aligned}
& =\quad 1.316 .790 \mathrm{lt} / \text { hari } \\
& =15,24 \mathrm{lt} / \mathrm{dt}
\end{aligned}
$$

Kapasitas alat 33 lt/dt

Layanan PDAM terhadap pelanggan :

$$
\frac{33 \mathrm{lt} / \mathrm{dt}}{15,24 \mathrm{lt} / \mathrm{dt}} \times 100 \%=216 \%
$$

Tabel 5 Target Layanan PDAM Sebesar $45 \%$

Sumber : Hasil Perhitungan

KESIMPULAN DAN SARAN 


\section{Kesimpulan}

1. Kemampuan pelayanan terhadap penduduk pada tahun 2021 dengan jumlah penduduk 32.514 jiwa, PDAM Kabupaten Pulang Pisau memberikan tingkat pelayanan dengan prosentase $216 \%$ dengan kapasitas produksi 33 lt/dt untuk layanan 45\% jumlah jiwa penduduk Kabupaten Pulang Pisau

2. Berdasarkan hasil analisis kebutuhan air bersih penduduk kota Pulang Pisau diketahui bahwa kebutuhan air bersih pada Tahun 2021 adalah sebesar 15,24 lt/dt.

\section{Saran}

1. Perlu meningkatkan sistem jaringan sehingga tingkat kebocoran kehilangan air yang tinggi dapat diminimalisir sekecil mungkin.

2. Sehubungan dengan peningkatan pelayanan PDAM untuk memenuhi seluruh kebutuhan penduduk Kota Pulang Pisau Tahun 2021 sebesar 33 lt/dt maka diperlukan penambahan kapasitas produksi air dari Instalansi Pengolahan Air di atas Tahun 2021.

\section{DAFTAR PUSTAKA}

Anonim, 2009, Diktat-Diktat Kuliah Rekayasa Penyehatan Lingkungan, Universitas Kristen Palangkaraya.

Anonim, 2009, Diktat-Diktat Kuliah Pengembangan Sumber Daya Air, Universitas Kristen Palangkaraya.

Badan Perencanaan Pembangunan Daerah dan Badan Pusat Statistik, 2010. Sukamara Dalam Angka 2010, Badan Perencanaan Pembangunan Daerah. Pemerintah Daerah Kabupaten Pulang Pisau.

C.Sutrisno, Totok dan Suciastuti, Eni, 1991, Teknologi Penyediaan Air Bersih, Penerbit Rineka Cipta.

Departemen Pekerjaan Umum Cipta Karya, 1996, Maintenance Of Pipeline jilid I dan II.

Direktorat Jenderal Cipta Karya, (1997), Aspek Pengaturan dan Penyelenggaraan Bintek/Wastek Bidang air Bersih, PLP, Penataan Bangunan dan Perumahan/Pemukiman.
Triadmodjo Nugroho, dan Haryanto,2001. Evaluasi Kehilangan Air Jaringan Air PDAM kota Semarang. Universitas Semarang.

Wikipedia, 2008. Air Bersih, Bisa Diakses di http://id.wikipedia.org/wiki/airbersih . 